\title{
The Impact of Securities Analysts' Prediction on the Market
}

\author{
Xiaoxiao Wu \\ Institute of Industrial Economics, Jinan University, Guangzhou, China \\ Email: Jasmine_wu1910@hotmail.com
}

How to cite this paper: Wu, X. X. (2017). The Impact of Securities Analysts' Prediction on the Market. Journal of Financial Risk Management, 6, 79-92. https://doi.org/10.4236/jfrm.2017.62007

Received: April 6, 2017

Accepted: May 8, 2017

Published: May 11, 2017

Copyright (C) 2017 by author and Scientific Research Publishing Inc. This work is licensed under the Creative Commons Attribution International License (CC BY 4.0).

http://creativecommons.org/licenses/by/4.0/

\begin{abstract}
Securities analysts' prediction has been a conception which is paid attention to in recent years' concern to the industry and academics, including the relationship between securities analysts' prediction and their characteristics. This paper is aimed to research how securities analysts' prediction influences the market. It is found that the impact capacity is generally weak in the market of China, and the consistency index of all the forecast accuracy indexes is especially important in determining the accuracy and the ability to predict the market.
\end{abstract}

\section{Keywords}

Securities Analysts' Prediction, Forecast Error, Predictive Accuracy, Stock Market, Securities Analyst

\section{Introduction}

The accuracy of the securities analysts' (hereinafter referred to as analysts) prediction has been a matter of considerable concern to the industry and academia. The basic role of the analysts is to integrate the existing information on the market and form a judgment on the future earnings of the company to provide investors with investment advice. With the accelerated transformation of China's capital market, analysts as an intermediary to provide information will play an increasingly important role. Therefore, the assessment of the analysts' ability to predict will be a more important topic. In general, the analysts' approach to the market can be divided into two broad categories: first, to integrate information on the existing market, in order to improve the transparency of corporate information and promote the flow of securities (Fang, 2007). The other is to provide a certain professional content of the forecast report, affecting the future expectations of the investors, thus affecting the securities gains (Guo \& Hong, 2009). 


\section{Literature Review}

In the mature capital market, securities analysts as an important part of information intermediaries have been generally recognized. However, in emerging market countries such as China, its ability to improve the efficiency of capital markets remains to be supported by empirical evidence. Fang (2007) argues that, on the whole, the accuracy of the analyst's prediction is significantly better than the random walk model, and the information disclosure status of listed companies will have an impact on the forecasting characteristics of securities analysts. The higher the transparency of information disclosure is, the higher the accuracy of analysts' forecasts will be. Zhu et al. (2007) investigated the influence of securities analysts on the efficiency of capital market operation by studying the relationship between securities analysts and stock price synchronization and stock price information content. Empirical evidence shows that, in general, the securities analyst's information search activity can increase the information content of the stock price, so that it contains more information on the company's fundamentals, and reduce the synchronization of stock prices, thereby enhancing the price as a guide role for the allocation of resources, and improve the efficiency of capital market operation. On the basis of the CAPM model, Yu et al. (2008) analyzed how the information intermediary influenced the capital market by analyzing the theoretical model of the relationship between the quality of the information intermediary and the cost of the equity capital. Further, based on the empirical evidence, after using the institutional environment and the simultaneous equations to control the supply side effect, the relationship between them is tested and the empirical results of the model are tested. The results show that the information intermediary can influence the capital cost of the enterprises by improving the future cash flow of the enterprises and reduce the information risk of the enterprises, and the relationship between the reputation of the information intermediary and the cost of the equity capital is negatively correlated. Chu et al. (2008) examines the impact of the consistency of the analyst's pricing forecast, the divergence of opinions, and the number of analysts' follow-up, by examining the observations of 353 IPO companies and 1323 analysts' pricing forecasts from 2000 to 2005 on the company's first day listed market performance. Among them, there is no significant difference between the consistency of analyst pricing forecast and the closing price of the company listed on the first day statistically, and the consistency of analyst pricing forecast can explain the closing price of the company listed on the first day well, which shows that analysts' predicting price is trustworthy. In contrast, Guo and Hong (2009) found that Chinese analysts' earnings predictions on listed companies were ineffective in China's securities analysts' empirical study, which shows that the actual weight of the granting of private information exceeds the effective weight of the private information in the formation of the rational Bayesian earnings forecast. However, the reason for the formation of inefficient and high-weight predictive behavior is not the subjective motivation of the analyst's overconfidence or the pursuit of stock trading commissions, but rather the subjective motives for 
higher display capabilities and the poor information disclosure of Chinese listed companies.

By using the data of Shenzhen Stock Exchange from 2010 to 2012, the paper makes an empirical study on the forecasting accuracy of Chinese analysts based on the corporate factors Ying et al. (2014). The study finds that the more optimistic the earnings forecast provided by the analysts is, the higher the volatility of the surplus is and the better the quality of the information disclosure of the listed company is, the higher the forecasting accuracy will be. The bigger the company is, the stronger the earnings management motivation is and the less predictable the surplus is, the lower the forecast accuracy will be. At the same time, from another point of view, Zhou and Huang (2014) systematically investigated the impact of securities analysts' prediction experience and historical forecast accuracy on the accuracy of cash flow forecast based on the cash flow forecast data released from 2007-2011. The study found that the firm-level experience was significantly positively correlated with the accuracy of cash flow forecast, indicating that the longer the analysts were tracking the duration of a particular listed company, the analysts would be able to acquire more private information and would be more able to obtain private information about that particular company.

In the case of foreign research, Gu and Wu (2003) argues that if the analysts' goal is to provide the most accurate prediction (the standard is the average for minimizing the absolute prediction error), the optimal forecast is the median of the income rather than the Mean. When the distribution of income is peaked, the forecast error will appear. When the size of the company is used as the variable, the empirical results show that the yield skewness is significantly related to the analyst's forecast error. At the same time, the empirical test confirmed that the stock market will automatically adjust according to the bias error caused by skewness. Bailey et al. (2003) argued that with the application of fair disclosure rules, the market behavior around earnings disclosure has not shown a significant change in earnings volatility, while the volume has increased significantly due to different opinions. Analysts predict that differences will increase, and differences in other measures and in the views of the parties suggest that the forecast for the next quarter will be more difficult. The numbers of companies that voluntarily disclose information increase, but they only disclose the current quarterly earnings. As a result, fair disclosure rules seem to increase the amount of information provided to the public and make greater demands on professional investors. Dhaliwal et al. (2012) analyzed the relationship between non-financial information disclosure and analysts' predictions based on the enterprise-level data from 31 countries, and defined the functions of independent CSR (CSR) reporting in financial markets. Independent CSR reports disclose non-financial information, and we find that the issuance of independent CSR reports is less relevant to analysts' forecasting errors, and this relationship is more pronounced in financial market-dominated countries. In countries where information is not transparent, independent CSR reports even play an important role in financial 
disclosure. Mohanram and Gode (2013) first sum up the previous study, and suggest that there is a weak correlation between the implied equity costs and the actual rate of return, and the predictable errors in the analysts' forecast are the probable cause. Furthermore, it is found that the deletion of the analysts' predictable error will lead to a stronger correlation between the implied equity cost and the actual rate of return after controlling the cash flow and the discount rate. The results confirm the effectiveness of the implied equity cost when estimating expected returns. Kim \& Song (2014) examine whether the previously published forecasts reflect the private information and other issues such as news and related events that the analyst understands by examining the stock's response to the analyst's forecast correction. The authors found that earnings management predictions had a significant impact on the accuracy of analysts' forecasts, and more importantly, they found that if the earnings management forecast was predicted, previous studies which found weak (strong) stock price forecasts to predict the earnings report for the previous quarter would be invalid. To some extent, earnings management forecasts are publicly disclosed, while the importance of the analysts in the process of information discovery was overestimated in previous studies.

The motivation of this paper comes from two contradictory literature conclusions. Hilary and Hsu (2013) noted in their article that the impact of analysts on the market comes from the consistency of predictions (measured by standard error estimates). They use the abnormal income as the surrogate variable of the analyst's prediction adjustment - information content (information), after controlling the accuracy of the analyst forecast (i.e. the absolute value of prediction error), the ability of consistency interpretation information content is better than accuracy. But the necessary premise of this regression is that the prediction error about the given "Enterprise-analysts" is a constant.

In general, compared with the existing literatures which study the determinants of the analyst's forecast ability, this paper focuses on the impact of the analyst's ability to predict on the market. The structure of this paper is organized as follows. The Section 1 is the introduction. And a literature review is performed in Section 2. Section 3 is devoted to describe the model and empirical design. Finally, section 4 concludes this work, giving the summary and putting forward development suggestions.

\section{Analyst Systemic Projection Deviation}

In this paper, we use the analyst forecast database in CSMAR database, the analyst forecast samples and actual samples of listed companies in China in 2002-2013. Taking the net profit as an example, we eliminated the sample observation of the missing net profit data, and got 426418 observation samples of Enterprise-analyst forecast. All of the variables involved in the following are also from the CSMAR database. We match the actual net profit achieved in the actual forecast date of the analyst on the last day of a year. We use this initial sample for statistical analysis, which shows in Table 1, in which the unit is 100 million 
Table 1. The descriptive statistics of analyst forecast.

\begin{tabular}{|c|c|c|c|c|c|c|c|}
\hline \multicolumn{8}{|c|}{ Panel A: Descriptive statistics } \\
\hline Variables & $\begin{array}{c}\text { Number of } \\
\text { observations }\end{array}$ & $\begin{array}{l}\text { Mean } \\
\text { value }\end{array}$ & \multicolumn{2}{|c|}{$\begin{array}{l}\text { Standard } \\
\text { deviation }\end{array}$} & \multicolumn{2}{|c|}{$\begin{array}{l}\text { Minimum } \\
\text { value }\end{array}$} & $\begin{array}{l}\text { Maximum } \\
\text { value }\end{array}$ \\
\hline Mnetpro & 426418 & 31.69 & \multicolumn{2}{|c|}{153.5} & \multicolumn{2}{|c|}{-140.5} & 2630 \\
\hline Fnetpro & 426418 & 33.09 & \multicolumn{2}{|c|}{154.0} & \multicolumn{2}{|c|}{-1395} & 3273 \\
\hline $\mathrm{FE}$ & 426418 & -1.395 & \multicolumn{2}{|c|}{34.63} & \multicolumn{2}{|c|}{-2775} & 2688 \\
\hline \multicolumn{8}{|c|}{ Panel B: Match $t$ test } \\
\hline \multicolumn{2}{|c|}{ Variables } & $\begin{array}{c}\text { Number of } \\
\text { observations }\end{array}$ & $\begin{array}{l}\text { Mean } \\
\text { value }\end{array}$ & $\begin{array}{l}\text { Standard } \\
\text { error }\end{array}$ & $\begin{array}{l}\text { Standard } \\
\text { deviation }\end{array}$ & \multicolumn{2}{|c|}{$\begin{array}{l}95 \% \text { confidence } \\
\text { region }\end{array}$} \\
\hline \multicolumn{2}{|c|}{ Mnetpro } & 426418 & 31.69 & 0.235 & 153.5 & 31.23 & 32.15 \\
\hline \multicolumn{2}{|c|}{ Fnetpro } & 426418 & 33.09 & 0.236 & 154.0 & 32.62 & 33.55 \\
\hline \multicolumn{2}{|c|}{ diff } & 426418 & -1.395 & 0.0530 & 34.63 & -1.499 & -1.291 \\
\hline \multicolumn{8}{|c|}{ mean $($ diff $)=$ mean $($ Mnetpro - Fnetpro $), t=-26.30$} \\
\hline \multicolumn{2}{|c|}{ H0: mean (diff) $=0$} & \multicolumn{3}{|c|}{ Variance: 426417} & & & \\
\hline \multicolumn{2}{|c|}{ Ha: mean (diff) $<0$} & \multicolumn{3}{|c|}{ Ha: mean(diff) $!=0$} & \multicolumn{3}{|c|}{ Ha: mean(diff) $>0$} \\
\hline \multicolumn{2}{|c|}{$\operatorname{Pr}(\mathrm{T}<\mathrm{t})=0.0000$} & \multicolumn{3}{|c|}{$\operatorname{Pr}(|\mathrm{T}|>|\mathrm{t}|)=0.0000$} & \multicolumn{3}{|c|}{$\operatorname{Pr}(\mathrm{T}>\mathrm{t})=1.0000$} \\
\hline
\end{tabular}

yuan. Panel A shows the sample of the analyst forecast samples (Fnetpro) and actual situation (Mnetpro) of the listed companies in China in 2002-2013. Panel $B$ shows the results of match $t$ test, the unit is 100 million yuan.

Rough analysis shows that China's analysts have a low level of forecast, that is, the forecast of analysts is lower than the net profit of nearly 100 million. According to the average annual net profit in the listed companies in China (about 3.2 billion yuan), this result is relatively large, indicating that the forecast of net profit of listed companies by Chinese analysts may be systematically underestimated. This conclusion is consistent with the "conservative estimates" noted by Hilary and Hsu (2013), that analysts may form their own private expectations in order to obtain in-house information from the enterprise, and therefore tend to be conservative. The result is that when market investors form expectations based on this prediction information, the performance of the business is easier to predict.

\section{Model and Empirical Test}

\subsection{Model}

In order to be able to characterize the analyst's ability to influence the stock market price, we modeled Hilary and Hsu (2013) to estimate the Beta of the analyst's ability to predict changes in the stock's Abnormal Return. All of the following variables are structured on a per-share basis for the purpose of reducing the difference in the number of companies that bring different shares. The Beta value is the main explanatory variable of this paper, which is defined as the relative change when the forecast is made at a certain point in the stock $j$, which is analyzed by the analyst $i$, relative to the company's earnings forecast per share 
at the previous point. It is recorded as delFeps and can be understood as an analyst's forecast. And the change can be known to the market, and then be used to calculate the non-normal rate of return for the next three days (if the release date is a non-trading day, the practice of this article will take the last three days) after the new forecast's release, which is recorded as $b h r 3 d$. And the rate of return is a difference between the market rate of return and the market share. The nonnormal rate of return can be understood as the market reaction after the change of an analyst's prediction, and this article assumes that the response represents a market reaction that the analyst predicts the change (Actually, there is no better way to filter out the response to the analyst). The bhr3d obtained when the analyst $i$ analyzed stock $j$ at all predicted and sub-prediction points (such as the forecast for 2013 that may include many different previous predictions) is made regression with delFeps, and the Beta coefficients of delFeps are obtained. The Beta coefficients are Defined as the "analyst's ability to influence the market" in this article.

After calculating the analyst's Beta coefficient for the same stock, the next is based on the analyst's forecasting error structure. Hilary and Hsu (2013) suggest that analyst's consistency Cons is particularly important for analysts to influence the market. In this paper, we use Beta coefficient to synchronize the consistency Cons and $\mathrm{AcCu}$ simultaneously to find that the former is more important. In addition to constructing the two variables, this paper constructs another variablemean square error by means of MSE.

First, the $F E$ is defined as the Realized Forecast Error, which is the difference between the final earnings forecast per share and the actual earnings forecast per share for the same stock in the same forecast period. In the traditional literature, the variables used to characterize the analyst's prediction accuracy can be defined as the mean of the absolute value of $F E$. In this paper, the name is also selected as the accuracy Accu. But some people think that if the analyst predicts the same stock several times at two units lower, but another analyst predicts at two units lower and higher half, though the prediction accuracy Accu is same for the two analysts, the former forecasts more consistently obviously. And if the investor is able to understand the analyst's forecast based on the Bayesian rule, the former will make the investor think that it is more accurate, as long as the experienced investor can find that it always underestimates the same size. Therefore, it is reasonable to define the standard deviation of $F E$ as the degree of consistency predicted by the analyst, that Cons may be the "accuracy" of the investor's mind. Finally, this new point is that, $A c c u$ focuses on the size of the prediction error, while Cons focuses on the prediction error fluctuations, and the combination of the two can be defined as the total deviation, using the idea of mean square error, that MSE is defined as the square root of the square of the $F E$. The formula for the three variables is defined as follows:

$$
\begin{aligned}
F E_{i, j, t} & =\text { Meps }_{i, j, t}-\text { Feps }_{i, j, t} \\
\text { Accu }_{i, j} & =\sum_{t}
\end{aligned}
$$




$$
\begin{aligned}
& \operatorname{Cons}_{i, j}=\sum_{t}\left(F E_{i, j, t}-\frac{1}{T} \sum_{t} F E_{i, j, t}\right)^{2} \\
& \operatorname{MSE}_{i, j}=\sum_{t}\left(F E_{i, j, t}\right)^{2}
\end{aligned}
$$

If the influence of the analyst's prediction on the market is stronger, it is predictable that $A c c u$ has a positive effect on Beta when the investors judge by the average absolute predictor error of the analysts. And so on, we can analyze the factors why the investors trust the analyst's prediction through the positive and negative impact of the Cons and MSE on Beta coefficient. This is also the main purpose of this regression.

As the study of this article for the processing of data, there are still many places worth considering. Some are put forward in several points as follows:

1) With regard to the analysts' predicting data of China, there is a majority of forecasts which are completed by several analysts at the same time. This paper argues that, different analysts may also analyze different stocks, so it is feasible to split the same forecast to the individual prediction. The other reason is that if these data are removed, the amount of data will be greatly reduced, and for the same forecast, among all the analysts, it is difficult to distinguish between primary and secondary, while other treatment is not reasonable. Finally, after removing the samples without the name of the analysts, and a few samples where more than 4 people to predict the deletion were deleted, and a total of 4531 analysts have been selected.

2) The data of this paper can be divided into three-dimensional panels, which is stocks, analysts, and prediction periods. But from the structure of the previous Beta coefficient, only two dimensions, stock and analyst are remained in the final regression, and they will be treated as a cross-section. However, in the sample screening, this article removes the samples that the analyst has predicted less than six times for the same forecast period (if there are few times for the forecast, Beta may be difficult to estimate), and the samples that the number of forecast periods for the same company's earnings per share is less than 2 periods (If the forecast period is too little, it will be difficult to calculate the forecast consistency and Cons is not accurate enough) will be removed. Therefore, it needs to be familiar with the three-dimensional panels (plus different predictions for the same forecast period, it can be made into a four-dimensional panel) data structure for these processes.

3) Different sample selections may affect the conclusion, however, the amount of data in China is not big, and so it should be as conservative as possible. In addition, there exists some time-consuming work in data processing, including Beta calculation for different stocks of different analysts. Due to the large amount of data and the number of regression, it is recommended to use subsamples and then regress, then the parallel processing will be faster. In consideration of different data merging, and the sample cycle under the large data samples, it is possible to speed up the speed of data analysis by streamlining data 
characteristics and using some data processing techniques in this paper.

Finally, there are 2965 samples for each firm (The number of analysts' forecast data is relatively small, compared with the foreign literature which has more than 30,000 data). The main regression equation is as follows:

$$
\operatorname{Beta}_{i, j}=\alpha_{0}+\alpha_{1} \operatorname{Cons}_{i, j}\left(\operatorname{Accu}_{i, j}, \operatorname{MSE}_{i, j}\right)+\alpha_{k} X_{i, j}^{k}+\varepsilon_{i, j}
$$

\subsection{Empirical Test}

In this paper, we use Beta to regress to Cons, $A c c u, M S E$, and control other variables that affect the extent to the impact which the analysts' prediction brings. In this article, we include the following three commonly used variables: Horizon, is defined as the difference between the forecast release and the final data disclosure period. The finalized period in this paper is usually December 31 each year, while the actual public period is about in March or April of the following year (the time when the annual report is published), so Horizon will have a lot of negative values. But because it does not affect the order from the actual disclosure period, so the negative values are still retained. Exper, is defined as the number of forecast for the same company in the same forecast period. As the samples with the number of forecast which is less than 6 times have been removed above, Exper will be greater than or equal to 6 at least. In this paper, we take logarithmic form of Exper. Cover, is defined as the number of tracking analysts for the same company. The data show that there are up to 26 analysts who have tracked the same company, and the average number of analysts tracking a company is 8.2, which is more than the data conclusion (Hilary \& Hsu, 2013). One of the reasons is that we have taken a split for the same forecast with different analysts. Finally, for the Beta and Horizon values, there are tailing processing (winsorize) for Beta 2. Beta can also be a negative minus the absolute value of the root processing Beta 3, and this article will try to use Beta 3 as the explanatory variable. In addition, for the Cons, $A c c u$ and MSE variable, they are handled into variables of the sort value under the different analysts in the same company, specifically using the rank function after the standard 0 to 1 of the sub-point value. The low original value will be transformed into the high value of the sort. In other words, the more the accuracy and the consistency are, the values of Cons, Accu will be higher, so as to avoid the inaccuracy caused by the data fluctuation. The variable uses prefix rafter transformation.

From Beta 2 in Table 2, the overall Beta is very small, and this is completely different from the data (Hilary \& Hsu, 2013). From this article, it suggests that the analyst's ability to influence the market price is generally weak, which may lead to the results of this article (The details are mentioned in detail). In addition to see the three variables Cons, Accu and MSE, it can be found that the three variables are greater than the median, and the standard deviation is relatively large, so the three data are quite right deviation, and it is reasonable to do sorting re-processing. The converted variables are $r C o n s, r A c c u, r M S E$. The rest of the variables are not described here. The overall data structure can be found in this 
Table 2. Empirical analysis variable description statistics.

\begin{tabular}{cccccc}
\hline Variable & Average & Mean & Std. Dev & Min & Max \\
\hline beta 2 & 0.012 & 0.007 & 0.070 & -0.126 & 0.162 \\
beta 3 & 0.037 & 0.083 & 0.230 & -0.355 & 0.403 \\
Cons & 0.230 & 0.129 & 0.351 & 0 & 9.301 \\
Accu & 0.201 & 0.112 & 0.295 & 0 & 5.819 \\
MSE & 0.266 & 0.144 & 0.405 & 0 & 9.567 \\
rCons & 0.500 & 0.500 & 0.231 & 0.037 & 0.963 \\
rAccu & 0.500 & 0.500 & 0.231 & 0.037 & 0.963 \\
rMSE & 0.500 & 0.500 & 0.231 & 0.037 & 0.963 \\
Exper & 2.206 & 2.197 & 0.351 & 1.792 & 3.932 \\
Horizon 2 & 118.6 & 66 & 174.2 & -77 & 546 \\
Cover & 8.199 & 7 & 6.296 & 1 & 26 \\
\hline
\end{tabular}

article that is not the same with the United States, so the regression results may not be the same.

The main empirical results are as follows.

The regression consists of 2965 valid samples in Table 3 . When only the $r$ Cons is placed as explanatory variable (1), the variable is significant at the $5 \%$ level, and the size of the coefficients is about 0.012. Compared with the data (Hilary \& Hsu, 2013), the coefficient is very large, and the reason can be attributed to the Beta 2 which is particularly small, but statistically significant for that variable. The stronger the consistency is, the higher the analyst's ability to influence the market will be. With the number of analyst' forecast and forecast period, and the number of analysts tracking the same company controlled (2), the variable coefficients are still significant and the size does not change much. When $r$ Cons is replaced into other two variables (3) (4), only $r M S E$ is significant at the $10 \%$ level, while $r A c c u$ is not significant, indicating that the investor's attention may not paid to the absolute size of the forecast error. But $r M S E$ still shows that Chinese investors are partially concerned about the absolute size of the forecast error. When the rCons, rAccu are taken at the same time into (5) and three indicators (6) are made regression, it is found that these variables were not significant yet. In fact there may be a highly linear relationship between the three variables. According to Hilary and Hsu (2013), consistency and accuracy are two dimensions of predictive error in this paper, but the data show that there is a strong linear correlation between these variables. From Table 4, the multivariate co-linearity VIF test of (5) and (6) shows that the co-linearity between the three variables is very strong. The highest VIF value has exceeded 10 , and the highest VIF value in model (5) has exceeded 3, which indicates that there exists co-linearity between them. Nonetheless, Compared the $r$ Cons results in the model (1) (2) (5) (6), it can be found that the coefficients are stable at about 0.01 whether the coefficients are significant or not. From the statistical results, although it is 
Table 3. Regression results of Beta 2.

\begin{tabular}{|c|c|c|c|c|c|c|}
\hline & (1) Beta 2 & (2) Beta 2 & (3) Beta 2 & (4) Beta 2 & (5) Beta 2 & (6) Beta 2 \\
\hline \multirow{2}{*}{ rCons } & $0.0119^{\star *}$ & $0.0118^{\star *}$ & & & 0.0123 & 0.0110 \\
\hline & $(2.13)$ & $(2.05)$ & & & (1.25) & $(0.98)$ \\
\hline \multirow{2}{*}{$r A c c u$} & & & 0.0095 & & -0.0006 & -0.0038 \\
\hline & & & (1.62) & & $(-0.06)$ & $(-0.22)$ \\
\hline \multirow{2}{*}{$r M S E$} & & & & $0.0105^{*}$ & & 0.0044 \\
\hline & & & & $(1.80)$ & & $(0.22)$ \\
\hline \multirow{2}{*}{ Exper } & & 0.0025 & 0.0024 & 0.0024 & 0.0025 & 0.0025 \\
\hline & & $(0.64)$ & $(0.61)$ & $(0.61)$ & $(0.64)$ & $(0.64)$ \\
\hline \multirow{2}{*}{ Horizon 2} & & $2.12 \mathrm{e}-06$ & $2.04 \mathrm{e}-06$ & $2.13 e-06$ & $2.05 e-06$ & $2.04 \mathrm{e}-06$ \\
\hline & & $(0.27)$ & $(0.26)$ & $(0.27)$ & $(0.26)$ & $(0.26)$ \\
\hline \multirow{2}{*}{ Cover } & & -0.0001 & -0.0001 & -0.0001 & -0.0001 & -0.0001 \\
\hline & & $(-0.63)$ & $(-0.63)$ & $(-0.62)$ & $(-0.63)$ & $(-0.63)$ \\
\hline \multirow{2}{*}{ cons } & $0.0062^{\star \star}$ & 0.0017 & 0.0031 & 0.0026 & 0.0017 & 0.0017 \\
\hline & $(2.02)$ & $(0.19)$ & $(0.34)$ & $(0.28)$ & $(0.19)$ & $(0.19)$ \\
\hline $\mathrm{N}$ & 2965 & 2965 & 2965 & 2965 & 2965 & 2965 \\
\hline R-sq & 0.002 & 0.002 & 0.001 & 0.001 & 0.002 & 0.002 \\
\hline AIC & -7317 & -7311 & -7310 & -7310 & -7309 & -7307 \\
\hline BIC & -7305 & -7281 & -7280 & -7280 & -7273 & -7265 \\
\hline
\end{tabular}

Table 4. VIF value.

\begin{tabular}{cc}
\hline Model & Max VIF \\
\hline$(5)$ & 3.19 \\
$(6)$ & 12.32 \\
\hline
\end{tabular}

found that the consistency of the analysts' prediction will significantly affect the ability to predict the impact of the market, the size is still too small.

The multiple co-linearity problems mentioned above will be analyzed further in Table 5. In view of the correlation coefficient matrix of the three indexes of $r C o n s$, and $r A c c u$, the correlation degree of the three variables is very high, and even if the correlation coefficient is reduced after the sorting transformation, it is still higher than 0.8 . From this point of view, although the preceding regression results show that investors are more concerned with the consistency of analysts' forecasts, there is a correlation between the consistency and the predicted absolute and mean square errors, which means that the prediction is more likely to be inclined to the lower absolute error and lower mean square error. This is reflected in the data of China, which is different from the data of the United States. Therefore, in the subsequent analysis, this article is still using $r A c c u$ and $r M S E$, 
and it will not put the three variables into the regression at the same time, because the co-linearity will inevitably lead to non-significant results.

In order to be consistent with the practice of Hilary and Hsu (2013), this article also uses Beta 3 as the explanatory variable, which is the square root of Beta 2. Since Beta is less than 1 in this article, the square root will increase the Beta value and try to avoid problems when the Beta value is too small. The regression results are as follows (Table 6).

Table 5. Correlation coefficient of three variables.

\begin{tabular}{cccc}
\hline Coeff. & rCons & rAccu & rMSE \\
rCons & 1.000 & & \\
rAccu & 0.8223 & 1.000 & \\
rMSE & 0.8690 & 0.9448 & MSE \\
Coeff. & Cons & Accu & \\
Cons & 1.000 & & \\
Accu & 0.9327 & 1.000 & 1.000 \\
MSE & 0.9746 & 0.9843 & \\
\hline
\end{tabular}

Table 6. Regression results of Beta 3.

\begin{tabular}{|c|c|c|c|c|c|c|}
\hline & (1) Beta 3 & (2) Beta 3 & (3) Beta 3 & (4) Beta 3 & (5) Beta 3 & (6) Beta 3 \\
\hline \multirow{2}{*}{ rCons } & $0.0477^{\star * *}$ & $0.0443^{* *}$ & & & 0.0411 & 0.0441 \\
\hline & $(2.62)$ & $(2.36)$ & & & (1.28) & $(1.20)$ \\
\hline \multirow{2}{*}{$r A c c u$} & & & $0.0380^{* *}$ & & 0.0040 & 0.0115 \\
\hline & & & (1.99) & & $(0.12)$ & $(0.20)$ \\
\hline \multirow{2}{*}{ rMSE } & & & & $0.0386^{\star *}$ & & -0.0105 \\
\hline & & & & $(2.04)$ & & $(-0.16)$ \\
\hline \multirow{2}{*}{ Exper } & & 0.0103 & 0.0098 & 0.01 & 0.0102 & 0.0102 \\
\hline & & $(0.83)$ & $(0.78)$ & $(0.80)$ & $(0.81)$ & $(0.81)$ \\
\hline \multirow{2}{*}{ Horizon 2} & & $-7.86 \mathrm{E}-06$ & $-7.48 \mathrm{E}-06$ & $-8.05 \mathrm{E}-06$ & $-7.43 \mathrm{E}-06$ & $-7.39 \mathrm{E}-06$ \\
\hline & & $(-0.31)$ & $(-0.29)$ & $(-0.31)$ & $(-0.29)$ & $(-0.29)$ \\
\hline \multirow{2}{*}{ Cover } & & -0.0005 & -0.0005 & -0.0005 & -0.0005 & -0.0005 \\
\hline & & $(-0.81)$ & $(-0.80)$ & $(-0.80)$ & $(-0.80)$ & $(-0.80)$ \\
\hline \multirow{2}{*}{ cons } & 0.0132 & -0.0025 & 0.0018 & 0.0010 & -0.0027 & -0.0027 \\
\hline & $(1.31)$ & $(-0.08)$ & $(0.06)$ & $(0.04)$ & $(-0.09)$ & $(-0.09)$ \\
\hline $\mathrm{N}$ & 2965 & 2965 & 2965 & 2965 & 2965 & 2965 \\
\hline $\mathrm{R}$-sq & 0.002 & 0.003 & 0.002 & 0.002 & 0.003 & 0.003 \\
\hline AIC & -312.7 & -308.1 & -306.5 & -306.7 & -306.1 & -304.2 \\
\hline BIC & -300.7 & -278.1 & -276.5 & -276.7 & -270.2 & -262.2 \\
\hline
\end{tabular}


Replacing Beta 3 as the explanatory variable, the regression results have improved compared to the previous results. Compared with the results of Beta 2 as the explanatory variable, rCons, $r A c c u$ and $r M S E$ regression results have improved significantly. Specifically, in Table 6 (1), the significant performance of the consistency variable reached $1 \%$, and after controlling the other variables in (2) (3) (4), the three indicators are significant, although the control variable is not significant itself, but it will not affect the conclusions of this article. In addition, when the three indicators regress alone, the regression coefficient is relatively close, indicating that the three indicators are able to represent the accuracy of the analyst's forecast, and from the data of China, which are different from the US data, the three variables are very relevant in (5) (6), and the coefficients of rCons and (1) (2) do not change greatly. Although the coefficients of $r A c c u$ become positive and non-significant at this time, the coefficients of rCons are still larger than $r A c c u$, which is consistent with the conclusions of Hilary and Hsu (2013), and compared to the two variables, consistency is more important. Also from the MSE point of view, after controlling the rCons, the coefficient still changes greatly, and non-significant. This regression further illustrates that the consistency of analysts' forecast is particularly important for predicting the ability to influence the market.

\section{Conclusion}

Based on the conclusions of Hilary and Hsu (2013), this paper validates the data of China, and adds the mean square error as a new prediction accuracy index. According to the forecast to adjust the stock rate of return to describe the analyst's ability to predict the impact on the market, and then taking the average absolute size of the forecast error as $A c c u$, standard deviation as Cons, mean square error as MSE, the three variables are used to measure the predictive accuracy, on behalf of three different aspects, while controlling other factors such as the degree of understanding of the company and the number of analysts tracking a company. It is found that there exists a high degree of linear correlation in the regression among the three indicators, and the three variables cannot represent their own predictive accuracy. In comparison with the three indicators, Cons was found to be the best to perform accuracy, and the result was the same as Hilary and Hsu (2013), therefore, the conclusion that consistency was the most important criterion was put forward. In general, the ability to predict the impact on the market in China is generally weaker, and investors are more concerned with predictive coherence.

Due to some data problems, the evidence to support the results is less than Hilary and Hsu (2013). At last, this article summarizes the following reasons, which need to be resolved later.

Firstly, to further discuss the weak ability of the impact on the market, before the announcement of the forecast made by the analysts, information has been obtained by institutional investors in the previous period to a large extent, and it has long been reflected in the stock price process. But there is another possibility 
that the forecast published by the analysts contains almost no information. Generally, the analyst's work performs differently inside and outside on the market. So if the information of the forecast contains little, the market will show little interest for its prediction, which will lead to overall small and non-significant Beta value. So there is need to analyze the data characteristics of Beta in order to be informed.

Secondly, it will be the high co-linearity problem among Cons, Accu and MSE. Unlike Hilary and Hsu (2013), there is a strong linear relationship between absolute and volatility in the analysts' forecasts of China. If the correlation between the absolute deviation and the rate of change is strong, it means that the analyst's consistency is not strong, or often positive and negative, and the analyst's forecast ability is relatively low. While from the aspects of the relative level of stocks, there exist inconsistent characteristics. Therefore, in order to improve the effectiveness of data regression, it should also solve the highly relevant issues among these indicators.

Finally, in addition to solving these key issues mentioned above, the paper also presents the following developments. Since analysts predict that they can influence the behavior of market investors, it can also be considered if the analyst's forecast can reverse the company's operating conditions or corporate governance. How the forecast is made can be further analyzed, and perhaps several of the more important parts of the forecasting elements can be researched. Anyway, analysts' predictions are still the most important topic.

\section{References}

Bailey, W., Li, H., Mao, C. X., \& Zhong, R. (2003). Regulation Fair Disclosure and Earnings Information: Market, Analyst, and Corporate Responses. The Journal of Finance, 58, 2487-2514. https://doi.org/10.1046/j.1540-6261.2003.00613.x

Chu, Y., \& Cang, Y. (2008). Is the Predicting Price Credible of the Financial Analysts-Evidence from the Stock Market of China. Management World, 3, 58-69.

Dhaliwal, D. S., Radhakrishnan, S., Tsang, A., \& Yang, Y. G. (2012). Nonfinancial Disclosure and Analyst Forecast Accuracy: International Evidence on Corporate Social Responsibility Disclosure. The Accounting Review, 87, 723-759.

https://doi.org/10.2308/accr-10218

Fang, J. (2007). The Transparency of Information Disclosure of Listed Company and the Predication of Securities Analyst. Journal of Financial Research, 40, 136-148.

$\mathrm{Gu}, \mathrm{Z}$. and Wu, J. S. (2003). Earnings Skewness and Analyst Forecast Bias. Journal of Accounting and Economics, 35, 5-29.

Guo, J., \& Hong, J. (2009). A Study on the Effectiveness of Earnings Forecast Behavior of Chinese Securities Analysts. Economic Research Journal, 11, 55-67.

Hilary, G., \& Hsu, C. (2013). Analyst Forecast Consistency. The Journal of Finance, 68, 271-297. https://doi.org/10.1111/j.1540-6261.2012.01800.x

Kim, Y., \& Song, M. (2015). Management Earnings Forecasts and Value of Analyst Forecast Revisions. Management Science, 61, 1663-1683. https://doi.org/10.2139/ssrn.2387902

Mohanram, P., \& Gode, D. (2013). Removing Predictable Analyst Forecast Errors to Improve Implied Cost of Equity Estimates. Review of Accounting Studies, 18, 443-478. 
https://doi.org/10.1007/s11142-012-9219-2

Ying, Y., \& Zhang, Y. (2014). Study of Influencing Factors on Analysts Forecast Accuracy: Based on Panel Data of Shenzhen Stock Exchange. Accounting and Finance, 2, 91-95.

Yu, L., Wang, Y., \& Chen, Z. (2008). Does Information Intermediary Have Economical Add-Value-Based on Theoretical and Empirical Evidences. Management World, 7, 134-144.

Zhou, D., \& Huang, Y. (2014). Predictive Experience, Accuracy of Historical Forecast and Cash Flow Forecast of Securities Analysts. The Chinese Certified Public Accoutant, 2, 73-81.

Zhu, H. et al. (2006). Financial Development, Soft Budget Constraints, and Firm Investment. Accounting Research, 18, 64-71.

Submit or recommend next manuscript to SCIRP and we will provide best service for you:

Accepting pre-submission inquiries through Email, Facebook, LinkedIn, Twitter, etc. A wide selection of journals (inclusive of 9 subjects, more than 200 journals).

Providing 24-hour high-quality service

User-friendly online submission system

Fair and swift peer-review system

Efficient typesetting and proofreading procedure

Display of the result of downloads and visits, as well as the number of cited articles

Maximum dissemination of your research work

Submit your manuscript at: http://papersubmission.scirp.org/

Or contact jfrm@scirp.org 